\title{
Ofertas de suplementos múltiplos para tourinhos Nelore na fase de recria em pastagens durante o período da seca: desempenho produtivo e características nutricionais ${ }^{1}$
}

\section{Marlos Oliveira Porto ${ }^{2}$, Mário Fonseca Paulino ${ }^{3}$, Edenio Detmann ${ }^{3}$, Sebastião de Campos Valadares Filho ${ }^{3}$, Maykel Franklin Lima Sales ${ }^{4}$, Jucilene Cavali ${ }^{2}$, Michele Lopes do Nascimento ${ }^{5}$, Tiago Sabella Acedo ${ }^{5}$}

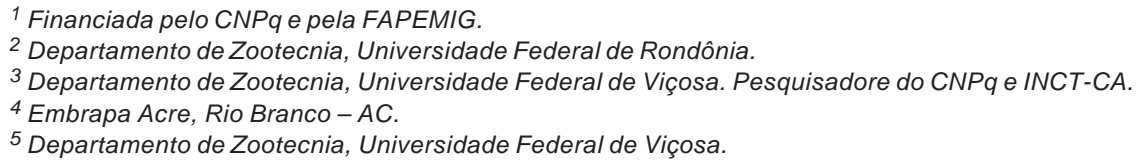

RESUMO - Avaliaram-se o desempenho produtivo e as características nutricionais em tourinhos Nelore em fase de recria, não-castrados, recebendo diferentes ofertas de suplementos em pastagem de Brachiaria decumbens, de julho a setembro de 2006. A área foi dividida em cinco piquetes de 2,0 ha, com disponibilidade média de matéria seca (MS) e matéria seca potencialmente digestível (MSpd) de 3,88 e 2,22 t/ha, respectivamente. Foram utilizados 30 bezerros com peso e idade iniciais médios de 230,0 \pm 6,14 kg e 8,5 \pm 0,18 meses, em delineamento inteiramente casualizado contendo cinco tratamentos: quatro ofertas de suplementos em comparação a mistura mineral (MM). Foram avaliados a MM (60 g/animal) e suplementos múltiplos, fornecidos diariamente nas quantidades de 0,5; 1,0; 1,5 e 2,0 kg/animal para suprir 300 g/dia de PB. Os animais responderam ao uso de suplementos múltiplos, ganhando mais peso (88,72\%) e apresentaram maiores níveis séricos de N-ureia (19,95 vs. 9,66) em comparação àqueles que receberam mistura mineral. Os animais sob suplementação apresentaram maiores consumos de MS, MO, EE, FDN, CNF e NDT e esses consumos aumentaram com os níveis de oferta de suplemento. A suplementação aumentou o coeficiente de digestão da maioria das variáveis avaliadas, independentemente do nível de suplemento fornecido. Os níveis mais moderados $(0,5 \mathrm{~kg})$ de suplementos múltiplos podem ser fornecidos aos tourinhos em fase de recria durante o período da seca para estimular o consumo de pasto, porém a máxima produção microbiana é obtida com oferta de 1 ,34 kg de suplemento. As melhores respostas de desempenho e características nutricionais podem ser obtidas com o fornecimento diário de suplemento em níveis de 0,5 a $1,34 \mathrm{~kg} / \mathrm{animal}$.

Palavras-chave: consumo, digestibilidade, gado de corte, ganho diário, pasto

\section{Offers of multiple supplements to crossbreds Nellore young bulls in the growing stage on pasture, during the dry season: productive performance and nutritional characteristics}

\begin{abstract}
Productive performance and nutritional characteristics of crossbreds Nellore young bulls, in the growing stage, receiving different supplement offers, from July to September 2006, grazing on Brachiaria decumbens pasture were evaluated. The area was divided in five paddocks of 2.0 ha, with availability of dry matter and potentially digestible dry matter of 3.88 and $2.22 \mathrm{t} / \mathrm{ha}$, respectively. Thirty animals of $230.0 \pm 6.14 \mathrm{~kg}$ initial weight and $8.5 \pm 0.18$ months of age were assigned in a completely randomized experimental design with five treatments, and four supplementation levels. Mineral mix (60 g/day) and multiple supplements, formulated to supply different supplementation levels in the amounts of 0.5, 1.0, 1.5 and $2.0 \mathrm{~kg} / \mathrm{animal}$ to supply $300 \mathrm{~g} /$ day of crude protein were evaluated. Animals responded to the use of multiples supplements, gaining more weight (88.72\%), in addition to showing higher seric N-urea levels (19.95 vs. 9.66), when compared with animals fed diets supplied with mineral mix. Animals under supplementation showed higher intake of DM, OM, EE, NDF, NFC and TDN in relation to animals without supplementation, and this intake increased with the levels of supplement offer. Supplementation increased the coefficient of digestion of the majority of variables, regardless of the supplementation level. More moderate levels $(0.5 \mathrm{~kg})$ of multiple supplement may be provided to young bulls in the growing stage, during the dry season, to stimulate intake of pasture; however the maximum microbial yield is achieved with $1.34 \mathrm{~kg}$ of supplement. The best responses of performance and nutritional characteristics can be obtained with dairy supply of supplement in levels of 0.5 to $1.34 \mathrm{~kg} / \mathrm{animal}$.
\end{abstract}

Key Words: beef cattle, daily gain, digestibility, intake, pasture

Recebido em 5/7/2010 e aprovado em 29/12/2010.

Correspondências devem ser enviadas para: mportoufv@pop.com.br 


\section{Introdução}

O aumento da oferta de alimentos concentrados para bovinos de corte é inevitável, uma vez que o melhoramento genético dos animais eleva também suas exigências nutricionais. Dessa forma, na pecuária moderna, os planos nutricionais para bovinos de corte em pastejo são cada vez mais baseados em fontes suplementares para melhor ajuste da dieta fornecida às exigências nutricionais dos animais.

A suplementação com compostos nitrogenados durante o período seco do ano tem como premissa básica aumentar o consumo de pasto, melhorar a degradação da parede celular e acelerar a passagem dos componentes indesejáveis da dieta. O aumento no desempenho animal por meio da suplementação proteica pode não ser devido apenas ao maior consumo de forragem, mas a mudanças na digestibilidade ou na eficiência de utilização dos nutrientes (Sampaio et al., 2009).

No período seco do ano, devido à má qualidade da forragem, com baixos níveis de proteína bruta e altas concentrações de fibra em detergente neutro com grande porção lignificada, têm sido muito utilizados pelos produtores de gado de corte o diferimento do pasto e o fornecimento de sal mineral com ureia e proteinados de baixo consumo, na quantidade de $1 \mathrm{~g} / \mathrm{kg}$ de peso corporal, para animais em fase de recria. A intensidade da resposta de um suplemento proteico dependerá da qualidade e da disponibilidade da pastagem. Apesar disso, os ganhos de peso obtidos ainda são negativos ou muito baixos (Paulino \& Ruas, 1988) e podem comprometer o sistema produtivo, devido ao longo período em que os animais ficam na propriedade na fase de recria.

Neste contexto, o uso de maiores quantidades de insumo como alimentos energéticos poderia trazer benefícios ao sistema de produção, reduzindo o tempo dos animais na fase de recria e acelerando o giro do capital investido na atividade.

Assim, o objetivo neste trabalho foi avaliar o desempenho produtivo, o consumo e a digestibilidade em tourinhos nelores em fase de recria em pastagens de Brachiaria decumbens Stapf recebendo suplementos múltiplos durante o período da seca.

\section{Material e Métodos}

O experimento foi conduzido nas dependências do Setor de Gado de Corte do Departamento de Zootecnia da Universidade Federal de Viçosa, em Viçosa, Minas Gerais, entre os meses de julho e setembro de 2006, totalizando 84 dias (três períodos de 28 dias). Na Estação Meteorológica da universidade foram obtidos os dados climáticos relativos a temperatura e precipitação, durante os ensaios a campo (Figura 1).

Foram utilizados para avaliação do desempenho produtivo 30 tourinhos Nelore não-castrados com idades e pesos médios iniciais de 8,5 \pm 0,18 meses e $230 \pm 6,14 \mathrm{~kg}$, respectivamente. Foram utilizadas seis repetições para cada tratamento.

Foi destinada aos animais área experimental de 10 hectares, constituída por cinco piquetes de 2,0 ha, cobertos uniformemente com Brachiaria decumbens Stapf, providos de bebedouros e cochos cobertos. A cada 14 dias, os animais foram rotacionados entre os piquetes visando à eliminação de possíveis efeitos de piquetes sobre os tratamentos (o suplemento acompanha o grupo de animais), ou seja, duas vezes por período.

Foram avaliadas quatro ofertas de suplementos múltiplos, formulados para atender diferentes níveis de energia. Os suplementos foram avaliados em comparação ao fornecimento de mistura mineral e foram compostos de diferentes proporções (Tabela 1) dos seguintes ingredientes: farelo de soja, grão de milho triturado, mistura ureia:sulfato de amônia (9:1) e mistura mineral (MM) e oferecidos nas quantidades 0,$5 ; 1,0 ; 1,5$ e 2,0 kg/animal para atender 10 , 20, 30 e 40\% das exigências de nutrientes digestíveis totais, respectivamente, recomendados pelo NRC (1996) para um novilho de $230 \mathrm{~kg}$ com ganho médio diário de $0,7 \mathrm{~kg}$, com fornecimento de $300 \mathrm{~g}$ de PB/animal/dia, atendendo aproximadamente $40 \%$ das exigências de $\mathrm{PB}$. Os suplementos foram fornecidos diariamente, às $10 \mathrm{~h}$, em comedouro conjunto, dimensionado para permitir o acesso simultâneo dos animais.

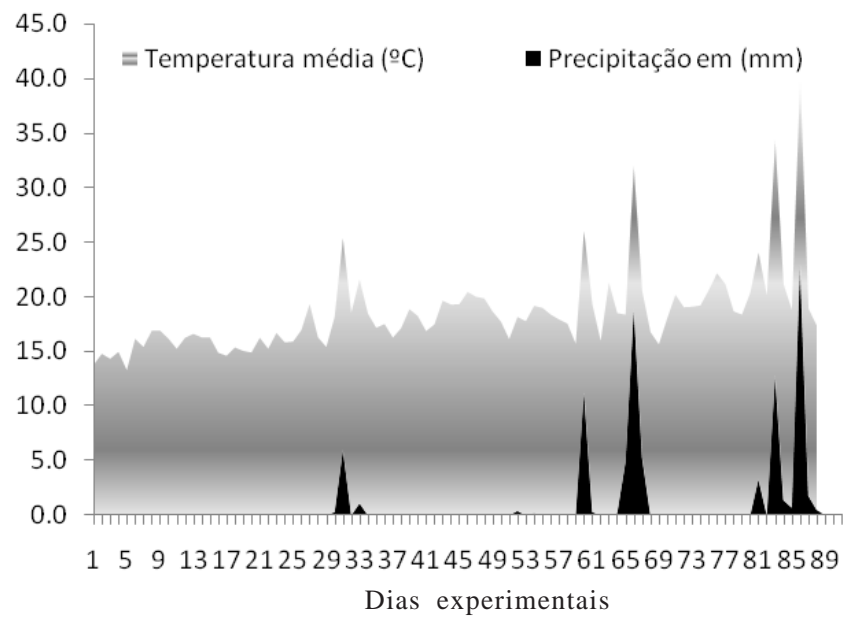

Figura 1 - Dados climáticos e de temperatura $\left({ }^{\circ} \mathrm{C}\right)$ e precipitação $(\mathrm{mm})$ durante os dias experimentais. 
Tabela 1 - Composição percentual dos suplementos, com base na matéria natural

\begin{tabular}{|c|c|c|c|c|c|}
\hline \multirow[t]{2}{*}{ Ingrediente } & \multirow[t]{2}{*}{ Mistura mineral } & \multicolumn{4}{|c|}{ Oferta de suplemento (kg) } \\
\hline & & 0,5 & 1,0 & 1,5 & 2,0 \\
\hline & & \multicolumn{4}{|c|}{ Proporção (\%) } \\
\hline Mistura mineral & 100,0 & 10,7 & 5,7 & 3,8 & 2,3 \\
\hline Ureia/sulfato de amônio (9:1) & - & 6,9 & 3,6 & 2,5 & 1,9 \\
\hline Farelo de soja & - & 78,4 & 28,0 & 9,9 & 0,5 \\
\hline Grão de milho triturado & - & 4,0 & 62,7 & 83,8 & 95,2 \\
\hline Total & 100,0 & 100,0 & 100,0 & 100,0 & 100,0 \\
\hline
\end{tabular}

Ao início do experimento, todos os animais foram submetidos ao controle de ecto e endoparasitos e, durante o período experimental, quando necessário, realizaram-se combates contra possíveis reinfestações.

Os animais foram pesados no início e ao final do experimento, sem jejum, sempre pela manhã, objetivando reduzir a interferência de possíveis alterações no ambiente ruminal que pudessem prejudicar o crescimento microbiano e alterar o consumo e o desempenho dos animais.

Foram realizadas pesagens e mensurações da altura, na região da garupa, dos animais com o objetivo de monitorar o desempenho dos animais. O ganho de peso total (GPT) dos tourinhos foi estimado pela diferença entre o peso final e o inicial, e o ganho médio diário, pela razão do GTP pelo número de dias experimentais.

No 14ํㅡㄹ dia de cada período experimental, foi realizada a coleta do pasto para avaliação da disponibilidade total de matéria seca (MS), pelo corte a $5 \mathrm{~cm}$ do solo de quatro áreas delimitadas por um quadrado metálico de $0,5 \times 0,5 \mathrm{~m}$, selecionados aleatoriamente em cada piquete experimental, para posterior quantificação da disponibilidade total de MS e MS potencialmente digestível (MSpd)/ha e das disponibilidades de MS de folha verde, folha seca, colmo verde e colmo seco/ha em cada piquete experimental. Essa amostra foi pesada e levada imediatamente a estufa com circulação forçada de ar $\left(60^{\circ} \mathrm{C}\right)$.

Procedeu-se à avaliação do teor de MSpd da massa total do pasto, segundo Paulino et al. (2006), pela seguinte equação:

MSpd = 0,98 $(100-$ FDN $)+($ FDN - FDNi $)$, em que: FDN = fibra em detergente neutro; e FDNi = fibra em detergente neutro indigestível.

As amostras para avaliação qualitativa do pasto consumido pelos animais foram obtidas no $14^{\circ}$ dia de cada período experimental, via simulação manual de pastejo. Nas amostras do pasto e dos alimentos concentrados, foram estimados os teores de MS, PB, cinzas e extrato etéreo (EE) de acordo com Silva \& Queiroz (2002); fibra em detergente neutro, com uso de amilase, fazendo as devidas correções para proteína e cinzas, segundo Mertens (2002), e fibra em detergente ácido (FDA) e lignina (ácido sulfúrico 72\%), segundo os métodos de Van Soest \& Robertson (1985). Os teores de fibra em detergente neutro indigestível e fibra em detergente ácido indigestível (FDAi) foram obtidos após incubação in situ por 264 horas conforme proposto por Casali et al. (2008). Os teores de nitrogênio insolúvel em detergente neutro(NIDN) e nitrogênio insolúvel em detergente ácido (NIDA) foram estimados conforme descrição de Licitra et al. (1996).

Nos suplementos a quantificação dos carboidratos não-fibrosos (CNF) foi feita de acordo com Hall (2000):

$\mathrm{CNF}=100-[(\% \mathrm{~PB}-\% \mathrm{~PB}$ da ureia $+\%$ de ureia $)+$ $\%$ FDNcp $+\%$ EE + \%cinzas ]

em que: $F D N c p$ = fibra em detergente neutro corrigida para cinzas e proteína.

Os teores de proteína degradável no rúmen (PDR) foram estimados segundo recomendações do NRC (2001). Foram utilizados os seguintes valores das frações (a) e (b) e a taxa de degradação da fração b (c): 21,93; 74,21; e 4,03 para o milho e 18,21; 78,59; 9,90 para o farelo de soja e 33,97; 25,52; 7,96 para o pasto (Valadares Filho et al., 2006a), e o valor da taxa de passagem (Kp) utilizado foi de 5,00\%/hora.

$\mathrm{O}$ experimento foi analisado em delineamento inteiramente casualizado, e as comparações entre médias de tratamentos realizadas por análises de variância e regressão a $10 \%$ de significância.

Foram utilizados os 30 tourinhos Nelore do ensaio de desempenho produtivo para estimar o consumo e os coeficientes de digestibilidade, assim como a produção microbiana e a eficiência de síntese.

O experimento foi estruturado em delineamento inteiramente casualizado, com cinco tratamentos e seis repetições. No quinto dia do segundo período experimental, iniciou-se o ensaio, com duração de 10 dias, sendo sete destinados à adaptação dos animais ao óxido crômico e dióxido de titânio $\left(\mathrm{TiO}_{2}\right)$, conforme indicações de Titgemeyer et al. (2001), e três dias de coletas de fezes em horários diferenciados, 16 h, 12 h e 8 h, visando obter amostras de 
fezes representativas de cada animal durante o período experimental.

O fornecimento óxido crômico aos animais foi realizado do $1 \underline{0}$ ao 9o dia experimental, na quantidade de $10 \mathrm{~g} / \mathrm{animal} /$ dia, acondicionado em cartuchos de papel e introduzido, com uso de aplicador, via esôfago dos animais, às $11 \mathrm{~h}$.

A excreção da matéria seca fecal foi estimada com base na razão entre a quantidade do indicador fornecido e sua concentração nas fezes:

Matéria seca fecal ${ }_{(\mathrm{g} / \mathrm{dia})}=$ [quantidade fornecida do indicador $_{(\mathrm{g})}$ /concentração do indicador nas fezes $\left.{ }_{(\%)}\right] \times 100$

Para quantificação do consumo individual de suplementos, foram fornecidos diariamente $10 \mathrm{~g}$ de $\mathrm{TiO}_{2} /$ animal, homogeneizados ao suplemento imediatamente antes do fornecimento ao grupo. Para cálculo, utilizou-se a seguinte equação de Valadares Filho et al. (2006b):

$\mathrm{CMSS}_{(\mathrm{kg} / \mathrm{dia})}=[\mathrm{EF} \times(\mathrm{CTiF})] / \mathrm{CTiS}$, em que: $\mathrm{CTiF}=$ concentração de $\mathrm{TiO}_{2}$ nas fezes $(\mathrm{kg} / \mathrm{kg})$ e CTiS = concentração de $\mathrm{TiO}_{2}$ no suplemento $(\mathrm{kg} / \mathrm{kg})$.

No quinto dia do período experimental, foi coletada amostra do pasto nos piquetes dos tourinhos utilizando-se a mesma metodologia descrita acima. A amostragem do pasto consumido foi feita via simulação manual de pastejo.

As fezes foram coletadas diretamente no reto ou rapidamente após a defecação dos animais, em quantidades aproximadas de $200 \mathrm{~g}$. As amostras foram identificadas por animal e secas em estufa com circulação forçada de $\operatorname{ar}\left(60^{\circ} \mathrm{C}\right)$. Após esse período, foram moídas em moinho com peneira com porosidade de $1 \mathrm{~mm}$ e armazenadas como amostras compostas por animal no período.

A estimação do consumo voluntário foi realizada utilizando-se como indicador interno a FDA indigestível, empregando-se a equação proposta por Detmann et al. (2001): CMS $(\mathrm{kg} / \mathrm{dia})=\{[(\mathrm{EF} \times \mathrm{CIF})-\mathrm{IS}] / \mathrm{CIFO}\}+\mathrm{CMSS}$ em que: $\mathrm{CIF}=$ concentração do indicador nas fezes $(\mathrm{kg} / \mathrm{kg})$; CIFO = concentração do indicador na forragem $(\mathrm{kg} / \mathrm{kg})$; CMSS = consumo de matéria seca de suplemento $(\mathrm{kg} / \mathrm{dia})$; $\mathrm{EF}$ = excreção fecal (kg/dia); e IS = indicador do suplemento (kg/dia).

A variação ( $\triangle \mathrm{MSP}, \mathrm{kg} / \mathrm{kg}$ ) no consumo de MS de pasto (CMSP) em função do consumo de MS de suplemento (CMSS) foi calculada pela seguinte equação:

$\Delta \mathrm{MSP}(\mathrm{kg} / \mathrm{kg})=\left(\mathrm{CMSP}_{\text {Supl }}-\mathrm{CMSP}_{\mathrm{MM}}\right) / \mathrm{CMSS}$ em que: $\mathrm{CMSP}_{\text {supl }}=\mathrm{CMSP}$ dos animais sob suplementação (kg/dia); $\mathrm{CMSP}_{\mathrm{MM}}=\mathrm{CMSP}$ dos animais recebendo apenas mistura mineral (kg/dia).

No último dia do período de digestibilidade, foi realizada a coleta de amostras spot de urina $(10 \mathrm{~mL})$, em micção espontânea dos animais, e de sangue, realizadas aproximadamente 4 horas após o fornecimento do suplemento. Após a coleta, as amostras de urina foram diluídas em $40 \mathrm{~mL}$ de $\mathrm{H}_{2} \mathrm{SO}_{4} 0,036 \mathrm{~N}$ e congeladas a $-20{ }^{\circ} \mathrm{C}$ para posterior determinação dos teores de creatinina, $\mathrm{N}$-ureia (teor de ureia X o fator 0,466) e derivados de purina, segundo Valadares et al. (1999), utilizando-se o método colorimétrico. As amostras de sangue foram coletadas ao final do período de coleta de urina utilizando-se kits comerciais a vácuo, com gel acelerador da coagulação, sendo as amostras imediatamente centrifugadas e o plasma congelado.

As amostras de urina foram analisadas quanto aos teores de creatinina, empregando-se kits comerciais e utilizando o método colorimétrico. O cálculo do volume urinário diário foi feito empregando-se a relação entre a excreção diária de creatinina (EC) e adotando-se como referência a equação proposta por Chizzotti (2004) e sua concentração nas amostras spot: $\mathrm{EC}_{(\mathrm{mg} / \mathrm{kgPV})}=32,27 \times$ $0,01093 \times \mathrm{PV}$

Dessa forma, a excreção urinária diária de compostos nitrogenados foi o produto entre sua concentração nas amostras spot e o valor estimado de volume urinário.

As análises de alantoína e de ácido úrico na urina foram feitas pelo método colorimétrico, conforme método de Fujihara et al. (1987), citados por Chen \& Gomes (1992). A excreção total de derivados de purinas foi calculada pela soma das quantidades de alantoína e ácido úrico excretados na urina, expressas em mmol/dia.

As purinas absorvidas (Y, mmol/dia) foram calculadas a partir da excreção de derivados de purinas (X, mmol/dia), por intermédio da equação $\mathrm{Y}=\left(\mathrm{X}-0,385 \mathrm{PV}^{0,75}\right) / 0,85$, em que 0,85 é a recuperação de purinas absorvidas como derivados de purinas e $0,385 \mathrm{PV}^{0,75}$, a contribuição endógena para a excreção de purinas (Verbic et al., 1990).

A síntese ruminal de compostos nitrogenados (Z,g Nmic/dia) foi calculada em função das purinas absorvidas (Y, mmol/dia) utilizando-se a equação descrita por Chen \& Gomes (1992), com exceção da relação N purinas:N total das bactérias de 0,134, conforme Valadares et al. (1999): $\mathrm{Z}=70 \mathrm{Y} / 0,83 \times 0,134 \times 1000$, em que 70 é o conteúdo de $\mathrm{N}$ de purinas (mgN/mol); 0,134, a relação $\mathrm{N}$ purinas: $\mathrm{N}$ total nas bactérias; e 0,83, a digestibilidade das purinas bacterianas.

A eficiência microbiana foi expressa pelas unidades: g PB microbiana/kg de nutrientes digestíveis totais (g PBmic/kg NDT).

Todo o material coletado foi imediatamente congelado em freezer a $-20{ }^{\circ} \mathrm{C}$ para posterior análise no Laboratório de Nutrição Animal do Departamento de Zootecnia da Universidade Federal de Viçosa. As análises químicas foram realizadas de acordo com as técnicas descritas no ensaio de desempenho produtivo (Tabela 2). 
Tabela 2 - Composição química dos suplementos e pastos de Brachiaria decumbens

\begin{tabular}{|c|c|c|c|c|c|c|c|}
\hline \multirow[t]{2}{*}{ Item } & \multirow[t]{2}{*}{ Mistura mineral } & \multicolumn{4}{|c|}{ Oferta de suplemento (kg) } & \multirow[b]{2}{*}{ Pasto $^{1}$} & \multirow[b]{2}{*}{ Pasto $^{2}$} \\
\hline & & 0,5 & 1,0 & 1,5 & 2,0 & & \\
\hline Matéria seca, MS & 98,20 & 88,70 & 87,34 & 86,85 & 86,51 & 49,17 & $44,15 \pm 7,94$ \\
\hline Proteína bruta, PB (\%MS) & & 58,12 & 28,94 & 18,68 & 13,42 & 5,90 & $5,77 \pm 1,37$ \\
\hline Proteína degradada no rúmen $(\% \mathrm{MS})^{3}$ & & 46,19 & 22,33 & 13,98 & 9,69 & 2,93 & $2,85 \pm 0,68$ \\
\hline Proteína não degradada no rúmen $(\% \mathrm{MS})^{3}$ & & 11,94 & 6,61 & 4,70 & 3,73 & 2,97 & $2,91 \pm 0,69$ \\
\hline Proteína insolúvel em detergente neutro (\%PB) & & 5,57 & 2,33 & 1,16 & 0,56 & 65,33 & $50,19 \pm 8,54$ \\
\hline Fibra em detergente neutro (\%MS) & & 8,61 & 8,10 & 7,92 & 7,87 & 65,35 & $66,22 \pm 3,64$ \\
\hline Extrato etéreo (\%MS) & & 0,48 & 1,89 & 2,40 & 2,68 & 1,89 & $1,46 \pm 0,40$ \\
\hline Fibra e detergente ácido (\%MS) & & 7,97 & 3,91 & 2,46 & 1,71 & 35,61 & $34,61 \pm 3,13$ \\
\hline Matéria orgânica (\%MS) & & 77,32 & 88,11 & 92,00 & 94,52 & 91,41 & $91,68 \pm 0,34$ \\
\hline Carboidrato não fibroso (\%MS) & & 28,05 & 58,54 & 69,50 & 75,57 & 19,28 & $18,23 \pm 2,43$ \\
\hline Fibra em detergente neutro indigestível (\%MS) & & 2,03 & 2,59 & 2,80 & 2,92 & 27,13 & $29,40 \pm 4,34$ \\
\hline Fibra em detergente ácido indigestível (\%MS) & & 0,17 & 0,21 & 0,22 & 0,23 & 15,40 & $16,41 \pm 2,52$ \\
\hline
\end{tabular}

${ }^{1}$ Amostra de pastejo simulado obtida durante o ensaio de digestibilidade.

${ }^{2}$ Média e erro-padrão da média das amostras de pastejo simulado obtida durante o experimento.

3 Tabela brasileira de composição de alimentos para bovinos (Valadares Filho et al., 2006).

O experimento foi analisado em delineamento inteiramente casualizado e as comparações entre tratamentos realizadas por meio de contrastes ortogonais e ajustamento de equações de regressão linear $(\alpha=0,10)$. Os contrastes ortogonais foram: controle, mistura mineral vs. suplementos múltiplos; efeito linear, quadrático e cúbico do nível de suplemento múltiplo (Tabela 3).

\section{Resultados e Discussão}

As disponibilidades de matéria seca total (MST), matéria seca potencialmente digestível (MSpd) e demais componentes da planta, principalmente folha e colmo verdes, reduziram (Figura 2) do primeiro para o segundo período, aumentando no terceiro período, como resultado de condições climáticas favoráveis (Figura 1). Assim, a disponibilidade média de MST e MSpd foi de 3,88 e 2,22 t/ha, com digestibilidade potencial da forragem disponível de $57,30 \%$, grande parte dela passível de ser utilizada quando se fornecem suplementos aos animais (Paulino et al., 2006); principalmente, na época seca do ano onde o teor médio de PB do pasto foi de 5,77\%.

Tabela 3 - Distribuição dos coeficientes nos contrastes ortogonais empregados na decomposição das somas dos quadrados para tratamentos

\begin{tabular}{lccccc}
\hline Contraste & \multicolumn{4}{c}{ Coeficiente } \\
\cline { 3 - 6 } & Mistura mineral & $0,5 \mathrm{~kg}$ & $1,0 \mathrm{~kg}$ & $1,5 \mathrm{~kg}$ & $2,0 \mathrm{~kg}$ \\
\hline Controle & 4 & -1 & -1 & -1 & -1 \\
Efeito linear & 0 & -3 & -1 & +1 & +3 \\
Efeito quadrático & 0 & +1 & -1 & -1 & +1 \\
Efeito cúbico & 0 & -1 & +3 & -3 & +1 \\
\hline
\end{tabular}

De acordo com Paulino et al. (2008), a MSpd é uma medida integradora dos aspectos quantitativos e qualitativos do pasto, o que permite maior precisão da real capacidade de suporte e desempenho animal da área utilizada. A disponibilidade de MSpd (57,30\%) tem alta razão, 1,03 $(57,30 / 55,6)$ com as disponibilidades de MS de folha verde, folha seca e colmo verde (55,6\%), e a quantidade destes componentes pode ser um indicador prático dos aspectos qualiquantitativos do pasto disponível, aumentando a adoção do uso da MSpd como prática no campo, devido ao menor uso de análises laboratoriais. A oferta foi de 6,12 e 3,50 kg de MST e MSpd/100 kg de peso corporal/dia, respectivamente. A MSpd correspondeu a 73,33\% do recomendado por Paulino et al. (2004), valores de 4,0 a 5,0 kg de MSpd/100 kg de peso corporal/dia, para dar suporte à bovinocultura de precisão cujo objetivo é a exploração do limite genético do animal, visto que a disponibilidade de forragem é fator limitante no desempenho produtivo.

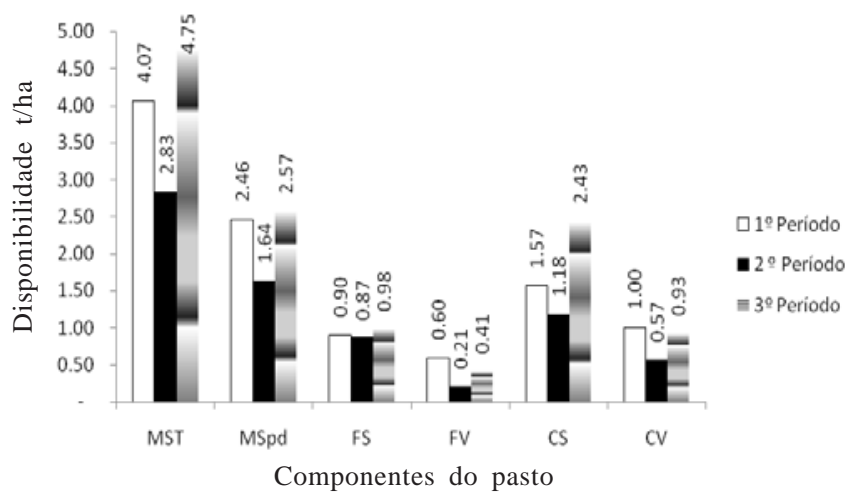

Figura 2 - Disponibilidade total de matéria seca (MST) e matéria seca potencialmente digestível (MSpd), folhas secas (FS), folhas verdes (FV), colmos secos (CS) e colmos verdes $(\mathrm{CV})$ do pasto.

R. Bras. Zootec., v.40, n.11, p.2548-2557, 2011 
Devido às características qualitativas (Tabela 2) e quantitativas (Figura 2) apresentadas pelo pasto, os animais responderam ao uso de suplementos múltiplos $(\mathrm{P}<0,10)$ ganhando mais peso $(88,72 \%)$ em comparação àqueles recebendo apenas mistura mineral (485 vs. 257 g/dia, respectivamente). O ganho médio diário (GMD) dos animais apresentou resposta linear às ofertas crescentes de suplemento $(\mathrm{P}<0,10)$.

As demais variáveis avaliadas relacionadas ao desempenho dos animais não foram influenciadas $(\mathrm{P}>0,10)$ pelos tratamentos (Tabela 4). Contudo, o peso corporal final dos animais sob suplementação foi 6,98\% superior ao daqueles do grupo controle $(\mathrm{MM})(\mathrm{P}<0,10)$, o que pode acelerar o retorno do capital total investido, devido ao menor tempo que os animais irão permanecer na fase de recria (Tabela 4 ).

Ressalta-se que, ao avaliar a conversão do suplemento adicional por quilograma de ganho adicional ao obtido pelos animais do grupo controle (CSP), verificou-se que, apesar do maior custo, devido à proporção dos ingredientes presentes em sua composição (Tabela 1), o suplemento fornecido na quantidade de 0,5 kg/dia é uma alternativa viável para a prática da suplementação, pois o preço do quilograma de peso corporal precisa ser superior a 2,59 (0,44 kg de suplemento/0,17 kg de ganho adicional) vezes o preço do quilograma do suplemento para viabilizar seu uso, diferente do verificado para as outras ofertas de suplemento (Tabela 4), como no caso da oferta de 2,0 kg/dia, na qual o preço do quilograma de peso corporal precisa ser 6,85 (1,94 kg de suplemento/0,283 kg de ganho adicional) vezes superior ao quilograma do suplemento para se tornar viável quando considerados esses dois fatores.
Os níveis séricos de $\mathrm{N}$-ureia foram maiores $(\mathrm{P}<0,10)$ para os animais sob suplementação (19,95 vs. 9,66 mg/dL) em comparação àqueles recebendo mistura mineral, valores próximos aos encontrados por Porto et al. (2008), que forneceram suplemento (23,0\% de PB) na quantidade de $1,0 \mathrm{~kg} /$ dia para tourinhos em terminação e observaram valores de 11,5 e 21,1 mg/dL de N-ureia, respectivamente, para os grupos sem e com suplementação. Isso ocorreu devido à ingestão de $\mathrm{PB}$ via suplemento múltiplo, que proporciona maior concentração de amônia ruminal. Essa amônia é absorvida e convertida em ureia no fígado; parte desta retorna ao rúmen via saliva ou pela parede ruminal, sendo que a quantidade reciclada depende da concentração absorvida. Quando falta energia no rúmen, maior quantidade de amônia é convertida em ureia no fígado e excretada na urina. $\mathrm{O}$ fornecimento de maior quantidade de energia para os tourinhos reduziu de forma linear $(\mathrm{P}<0,10)$ (Tabela 4) a concentração de N-ureia no soro, o que, teoricamente, poderia estar contribuindo para maior retenção de nitrogênio.

Os animais sob suplementação apresentaram maiores $(\mathrm{P}<0,10)$ consumos de MS, MO, EE, FDN, CNF e NDT em relação àqueles sem suplementação (Tabela 5). Estes consumos aumentaram com $(\mathrm{P}<0,10)$ as ofertas de suplemento aos tourinhos, com exceção do consumo de FDN.

O consumo de $\mathrm{PB}$ aumentou com uso dos suplementos múltiplos $(\mathrm{P}<0,10)$, porém o fornecimento crescente de suplementos não alterou os consumos de $\mathrm{PB}(\mathrm{P}<0,10)$, uma vez que os suplementos foram formulados para fornecer $300 \mathrm{~g}$ de PB/animal/dia (Tabela 5).

$O$ aumento $(\mathrm{P}<0,10)$ do consumo observado nas variáveis acima pode explicar em parte os maiores $(\mathrm{P}<0,10)$ ganhos dos animais recebendo suplementos múltiplos em

Tabela 4 - Médias ajustadas e coeficientes de variação (CV, \%) para as medidas biométricas, níveis séricos de N-ureia (NUS, mg/dL) e consumo de suplemento de acordo com a oferta de suplemento

\begin{tabular}{|c|c|c|c|c|c|c|c|c|c|c|}
\hline \multirow[t]{2}{*}{ Variável } & \multirow[t]{2}{*}{ Mistura mineral } & \multicolumn{4}{|c|}{ Oferta de suplemento (kg) } & \multicolumn{4}{|c|}{ Contraste } & \multirow[t]{2}{*}{ CV (\%) } \\
\hline & & 0,5 & 1,0 & 1,5 & 2,0 & S & $\mathrm{L}$ & Q & $\mathrm{C}$ & \\
\hline Peso corporal inicial, kg & 233,6 & 233,2 & 239,9 & 232,8 & 240,8 & - & - & - & - & - \\
\hline Peso corporal final, kg & 255,2 & 269,0 & 277,2 & 277,3 & 286 & ns & ns & ns & ns & 15,9 \\
\hline Altura inicial, cm & 125,5 & 124,0 & 124,7 & 126,2 & 126,2 & - & - & - & - & - \\
\hline Altura final, cm & 131,0 & 131,2 & 131,5 & 131,8 & 132,8 & ns & ns & ns & ns & 3,0 \\
\hline Razão peso altura inicial & 1,86 & 1,81 & 1,90 & 1,85 & 1,86 & - & - & - & - & - \\
\hline Ganho médio diário, g/animal ${ }^{1}$ & 257 & 427 & 444 & 530 & 540 & $* * *$ & $* * *$ & ns & ns & 17,7 \\
\hline Ganho diário adicional, g/animal & - & 170 & 187 & 273 & 283 & - & - & - & - & - \\
\hline $\mathrm{CSP}^{2}$ & - & 2,59 & 5,03 & 5,27 & 6,85 & - & - & - & - & - \\
\hline Consumo de suplemento ${ }^{3}$ & 0,06 & 0,50 & 1,00 & 1,50 & 2,00 & - & - & - & - & - \\
\hline N-ureia sérica ${ }^{1}$ & 9,66 & 24,33 & 19,89 & 19,30 & 16,27 & $* * *$ & $* * *$ & ns & ns & 23,0 \\
\hline
\end{tabular}

$\mathrm{S}=$ controle vs. suplementação, $\mathrm{L}=$ linear, $\mathrm{Q}=$ quadrático, $\mathrm{C}=$ cúbico significativo a $1 \%(* * *), 5 \%(* *)$ e $10 \%(*)$ de probabilidade e ns = não-significativo.

${ }^{1} \mathrm{GMD}=0,374+0,087 \mathrm{NE}\left(\mathrm{r}^{2}=90,17\right) ; \mathrm{NUS}=26,185-4,97 \mathrm{NE}\left(\mathrm{r}^{2}=93,21\right)$.

${ }^{2} \mathrm{CSP}=$ conversão de suplemento adicional por kg de ganho adicional ao obtido pelos animais do grupo controle.

${ }^{3}$ Matéria natural (kg/animal/dia). 
Tabela 5 - Médias ajustadas, probabilidade e coeficientes de variação (CV) para os consumos de nutrientes de acordo com a oferta de suplemento

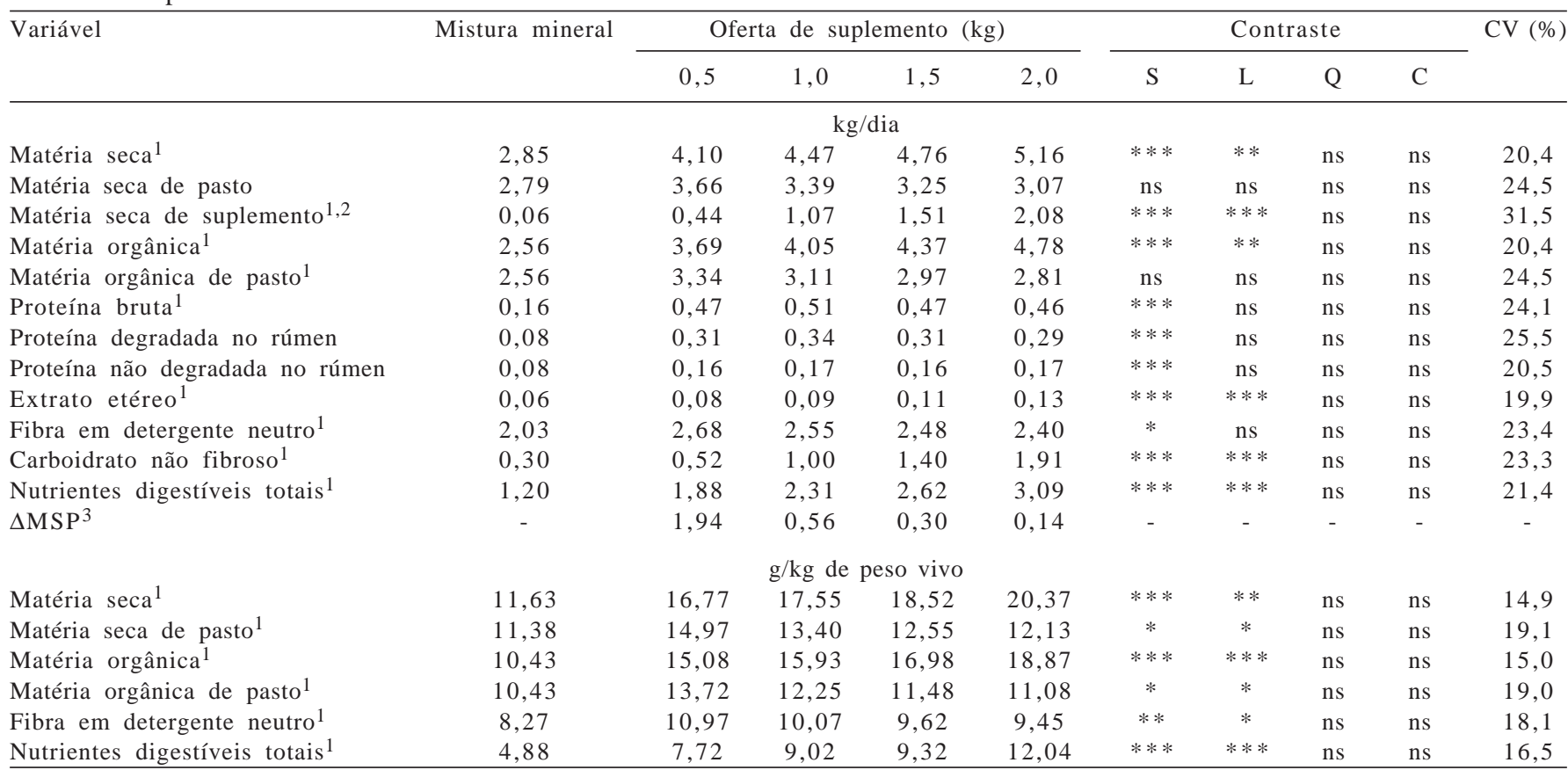

$\mathrm{S}$ = controle vs. suplementação, $\mathrm{L}$ = linear, $\mathrm{Q}$ = quadrático, $\mathrm{C}$ = cúbico significativo a $1 \%(* * *), 5 \%(* *)$ e $10 \%$ (*) de probabilidade e ns = não-significativo.

${ }_{1}$ Consumo de matéria seca $(\mathrm{MS})(\mathrm{kg} /$ dia $)=3,753+0,695 \mathrm{NE}\left(\mathrm{r}^{2}=99,68\right)$, MS de suplemento $(\mathrm{kg} / \mathrm{dia})=1,07 \mathrm{NE}-0,06\left(\mathrm{r}^{2}=99,55\right)$, matéria orgânica $(\mathrm{MO})(\mathrm{kg} / \mathrm{dia})=3,322+$ $0,721 \mathrm{NE}\left(\mathrm{r}^{2}=99,70\right)$, extrato etéreo $(\mathrm{kg} / \mathrm{dia})=0,067+0,027 \mathrm{NE}\left(\mathrm{r}^{2}=99,76\right)$, carboidrato não fibroso $(\mathrm{kg} / \mathrm{dia})=0,064+0,9143 \mathrm{E}\left(\mathrm{r}^{2}=99,85\right)$, nutrientes digestíveis totais $(\mathrm{NDT})(\mathrm{kg} / \mathrm{dia})=1,499+0,801 \mathrm{NE}\left(\mathrm{r}^{2}=99,59\right), \mathrm{MS}(\mathrm{g} / \mathrm{kg})=15,36+2,35 \mathrm{NE}\left(\mathrm{r}^{2}=95,72\right)$, MS de pasto $=(\mathrm{g} / \mathrm{kg})=15,6-1,87 \mathrm{NE}\left(\mathrm{r}^{2}=92,88\right), \mathrm{MO}(\mathrm{g} / \mathrm{kg})=13,62-2,48 \mathrm{NE}$ $\left(r^{2}=99,70\right)$, MO de pasto $(g / k g)=14,3-1,73 N E\left(r^{2}=96,40\right)$, fibra em detergente neutro $(g / k g)=11,21-0,94 N E\left(r^{2}=90,20\right) N D T(g / k g)=6,44+2,52 N E\left(r^{2}=89,84\right)$. 2 Consumo médio de suplemento durante o ensaio nutricional.

${ }^{3} \Delta \mathrm{MSP}=$ variação no consumo de MS de pasto em função do consumo de suplemento $(\mathrm{kg} / \mathrm{kg})$.

relação aos do grupo controle e o aumento linear no ganho de peso dos animais com os níveis crescentes de suplemento ofertado (Tabelas 4 e 5).

O consumo de suplemento múltiplo aumentou $(\mathrm{P}<0,10)$ de forma linear com o seu fornecimento, o que caracterizou os diferentes tratamentos.

Através da $\triangle \mathrm{MSP}$, do consumo de MO de pasto e FDN, observa-se (Tabela 5) que houve menor $(\mathrm{P}<0,10)$ participação do pasto como fonte de energia à medida que aumentava o fornecimento de suplemento, evidenciando que as menores ofertas de suplemento e os altos teores de PB em suplementos múltiplos de baixo consumo propiciam maior uso da forragem como fonte de energia, ou seja, maior consumo da dieta basal (Tabela 5). Souza (2007), suplementando bovinos alimentados com forragem tropical de baixa qualidade (5,16\% de PB) com compostos nitrogenados (ureia, sulfato de amônia e albumina) e carboidratos não-fibrosos (amido), verificou efeito interativo positivo para o nitrogênio combinado ou não com carboidratos, uma vez que a adição isolada de compostos nitrogenados promoveu maior consumo de FDN em comparação à sua combinação com carboidratos. Os resultados obtidos neste trabalho para a ingestão de MO de pasto (g/kg de peso corporal) estão de acordo com os dados da literatura, pois também foi observada redução $(\mathrm{P}<0,10)$ no consumo de FDN em g/kg de peso corporal à medida que se aumentou a quantidade de energia fornecida via suplemento, o que pode ser reflexo do menor teor de FDN na dieta.

Pela $\Delta$ MSP, observa-se que, para cada quilograma de suplemento múltiplo fornecido no nível de oferta de 0,5 kg/dia, ocorreu aumento de 1,94 kg no consumo de pasto, o que pode resultar em melhor desempenho animal, já que a quantidade de energia ingerida será maior. Quando considerados o NDT (42,63\%) da dieta dos animais do tratamento controle e o aumento do consumo de pasto $(\mathrm{P}<0,10)$ ( $\mathrm{g} / \mathrm{kg}$ de peso corporal) entre os animais recebendo suplemento, nota-se que houve aumento de $886 \mathrm{~g}$ de NDT ingerido/kg de suplemento fornecido aos animais deste grupo, o que justifica seus ganhos em relação aos do grupo controle. O consumo de NDT aumentou linearmente $(\mathrm{P}<0,10)$ com os níveis de suplementação, porém a participação do pasto foi reduzida.

Semelhantemente ao observado na determinação em $\mathrm{kg}$, quando o consumo de NDT foi expresso em g/kg de peso corporal, observou-se aumento linear $(\mathrm{P}<0,10)$ com as ofertas crescentes de suplemento (Tabela 5). Ressalta-se que os animais que receberam apenas $0,5 \mathrm{~kg} / \mathrm{dia}$ de suplemento apresentaram consumo de NDT 56,67\% superior 
ao daqueles que receberam apenas mistura mineral, o que contribuiu em grande parte para o maior $(P<0,10)$ desempenho (Tabela 4) dos animais recebendo o suplemento múltiplo na quantidade citada. Este resultado pode ser importante quando se visa abater animais mais jovens e dispõe de pouca mão-de-obra (para transporte de suplemento na propriedade) e investimento em infraestrutura (cochos).

A suplementação aumentou $(P<0,10)$ o coeficiente de digestibilidade para maioria das variáveis avaliadas no experimento, independentemente da oferta de suplemento (Tabela 6). Algumas exceções ocorreram para os coeficientes de digestibilidade da PB e da FDN; naquele houve aumento $(\mathrm{P}<0,10)$ da digestibilidade com a suplementação, contudo, à medida que foi aumentando a quantidade ofertada de suplemento, a digestibilidade da PB foi reduzindo e isto pode ter ocorrido, provavelmente, devido à queda na digestibilidade da FDN, uma vez que o teor de proteína ligada à parede celular foi alto (Tabela 2).

A digestibilidade da FDN reduziu com as ofertas de suplemento, provavelmente devido ao desequilíbrio de energia e proteína na dieta, uma vez que a relação NDT/PB foi de 4,0 e 6,71 na dieta dos animais que receberam 0,5 e 2,0 $\mathrm{kg}$ de suplemento, respectivamente, sendo que o BR-Corte recomenda relação de 4,37 $(2,780 / 0,636)$ para animais de $250 \mathrm{~kg}$ de peso corporal com ganho médio de $0,5 \mathrm{~kg} / \mathrm{dia}$. Isso pode ser observado também na concentração sérica de $\mathrm{N}$-ureia, que reduziu de forma linear $(\mathrm{P}<0,10)$ à medida que se aumentou a oferta de suplementos. Além disso, bactérias com maior taxa de crescimento e que utilizam o amido consomem rapidamente os compostos nitrogenados, o que leva à falta destes para as bactérias de lento crescimento, celulolíticas, reduzindo a digestão da fração fibrosa da dieta e liberando menos compostos nitrogenados presentes na parede celular, aumentando a passagem destes para as fezes (Tabela 6). O aumento do amido solúvel também pode retardar o processo de adesão dos microrganismos à celulose (Owens \& Goetsch, 1993). Contudo, isso não foi suficiente para prejudicar o desempenho dos animais (Tabela 4), já que o NDT observado da dieta aumentou linearmente $(\mathrm{P}<0,10)$ com o fornecimento de maior quantidade de suplemento.

O coeficiente de digestibilidade do CNF aumentou com a suplementação e com as ofertas crescentes de suplemento, logicamente devido à maior quantidade de grão de milho triturado fornecido aos animais via suplemento, o que acarretou maior consumo de CNF. Houve também redução no percentual dos nutrientes digestíveis advindos da fibra em detergente neutro (NDFDN) à medida que aumenta a oferta de concentrado aos animais (Tabela 6).

O consumo de suplemento aumentou $(\mathrm{P}<0,10)$ a produção de proteína microbiana (PMic) (Tabela 7) em comparação ao consumo de mistura mineral, certamente em razão da maior quantidade de substrato disponibilizado para os microrganismos ruminais. A produção de PMic apresentou comportamento quadrático com ponto de máxima produção de 404,47 g na quantidade de 1,34 kg de suplemento, isto ocorre talvez devido ao fato de apresentar a relação NDT/PB 4,92 (2,35/0,477) mais favorável para o crescimento microbiano, próximo do valor de 4,37 (2,780/ 0,636) estimado pelo BR-Corte (Valadares filho et al., 2006c). Os maiores valores numéricos para o consumo de PDR ocorreram no consumo próximo a 1,0 kg de suplemento, o que pode ter favorecido a maior produção de PMic.

A eficiência de síntese microbiana (EFMic) não diferiu entre os animais do grupo controle e os suplementados. Contudo, houve um comportamento quadrático com máxima eficiência 160,38 g/kg de NDT para oferta de 1,18 kg de suplemento (Tabela 7$)$. O ponto (1,18 kg) onde ocorreu a máxima EFMic foi inferior ao valor (1,34 kg) em que ocorreu

Tabela 6 - Médias ajustadas, probabilidade e coeficientes de variação (CV) para digestibilidade aparente total, de acordo com a oferta de suplemento

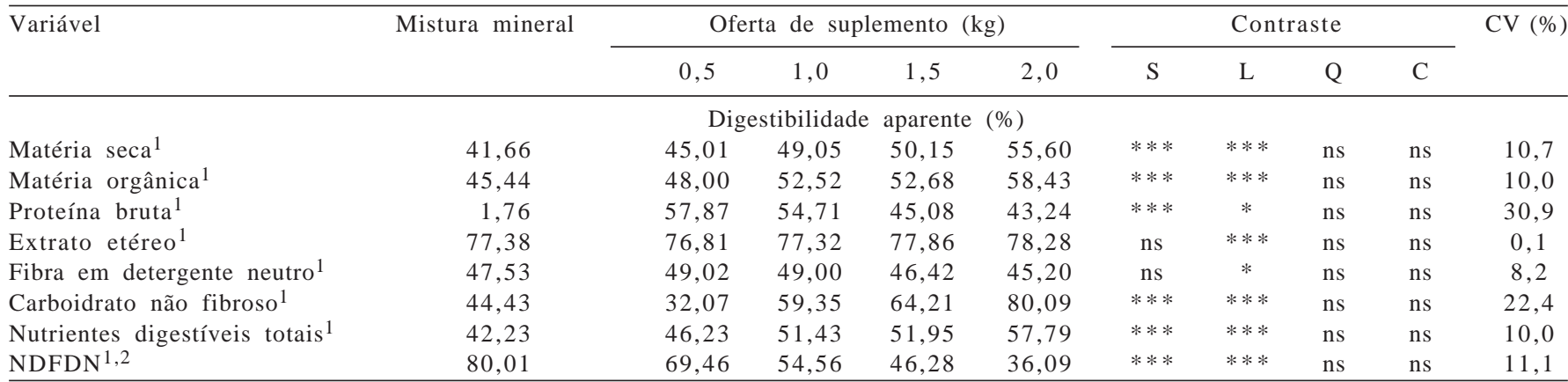

$\mathrm{S}=$ controle vs. suplementação, $\mathrm{L}=$ linear, $\mathrm{Q}=$ quadrático, $\mathrm{C}=$ cúbico significativo a $1 \%(* * *), 5 \%(* *)$ e $10 \%(*)$ de probabilidade e ns = não-significativo

${ }^{1}$ Digestibilidade da matéria seca $(\%)=41,57+7,30 \mathrm{NE}\left(\mathrm{r}^{2}=94,94\right)$, matéria orgânica $(\%)=44.73+7,09 \mathrm{NE}\left(\mathrm{r}^{2}=91,11\right)$, proteína bruta $(\%)=64,27-9,76 \mathrm{NE}\left(\mathrm{r}^{2}=93,72\right)$, extrato etéreo $(\%)=77,58+0,13 \mathrm{NE}\left(\mathrm{r}^{2}=97,12\right)$; fibra em detergente neutro $(\%)=50,71-2,99 \mathrm{NE}\left(\mathrm{r}^{2}=91,76\right)$, carboidrato não-fibroso $(\%)=19,59+33,13 \mathrm{NE}\left(\mathrm{r}^{2}=93,16\right)$, nutrientes digestíveis totais $(\%)=42,76+7,80 \mathrm{NE}\left(\mathrm{r}^{2}=93,09\right)$, NDFDN $\left(\%\right.$ do NDT) $=78,00-21,42 \mathrm{NE}\left(\mathrm{r}^{2}=97,67\right)$.

2 NDFDN = percentual dos nutrientes digestíveis advindos da fibra em detergente neutro, [consumo de FDN digerida $(\mathrm{kg}) /$ consumo de NDT (kg)] $\times 100$. 
Tabela 7 - Médias ajustadas, probabilidade e coeficientes de variação (CV) para produção, as eficiências de síntese de proteína microbiana ruminal e balanço de nitrogênio de acordo com a oferta de suplemento

\begin{tabular}{|c|c|c|c|c|c|c|c|c|c|c|}
\hline \multirow[t]{2}{*}{ Variável } & \multirow[t]{2}{*}{ Mistura mineral } & \multicolumn{4}{|c|}{ Oferta de suplemento (kg) } & \multicolumn{4}{|c|}{ Contraste } & \multirow[t]{2}{*}{ CV (\%) } \\
\hline & & 0,5 & 1,0 & 1,5 & 2,0 & S & $\mathrm{L}$ & Q & $\mathrm{C}$ & \\
\hline Proteína bruta microbiana ruminal (A), $\mathrm{g}^{1}$ & 176,4 & 226,1 & 358,2 & 349,9 & 292,0 & $* *$ & ns & $*$ & ns & 43,9 \\
\hline $\begin{array}{l}\text { (A) } / \mathrm{kg} \text { de nutrientes digestíveis } \\
\text { totais (B) }, \mathrm{g}^{\mathrm{kg}} \mathrm{kg}^{1}\end{array}$ & 143,4 & 121,7 & 157,2 & 142,2 & 98,2 & ns & ns & $*$ & ns & 43,1 \\
\hline Nitrogênio ingerido, g/dia & 23,05 & 75,70 & 81,87 & 75,87 & 73,78 & $* * *$ & ns & ns & ns & 24,6 \\
\hline Nitrogênio excretado nas fezes, g/dia & 22,53 & 31,66 & 35,88 & 42,22 & 38,52 & $* * *$ & ns & ns & ns & 28,8 \\
\hline Balanço de nitrogênio em função & $-25,28$ & 43,69 & 41,33 & 28,49 & 34,25 & $* * *$ & ns & ns & ns & 54,1 \\
\hline
\end{tabular}

do ingerido, \%

$\mathrm{S}=$ controle vs. suplementação, $\mathrm{L}=$ linear, $\mathrm{Q}=$ quadrático, $\mathrm{C}=$ cúbico significativo a $1 \%(* * *), 5 \%(* *)$ e $10 \%(*)$ de probabilidade e ns $=$ não-significativo.

${ }^{1} \mathrm{~A}=-73,91+713,44 \mathrm{NE}-266,00 \mathrm{NE}^{2}\left(\mathrm{R}^{2}=83,10\right), \mathrm{B}=33,14+215,45 \mathrm{NE}-91,20 \mathrm{NE}^{2}\left(\mathrm{R}^{2}=80,40\right)$.

a máxima produção de PMic. Segundo Owes \& Goetsch (1993), a produção microbiana total no rúmen geralmente aumenta com a quantidade de matéria orgânica fermentada no rúmen, e a eficiência microbiana não depende da produção microbiana.

Como ressaltado, a maior ingestão de nitrogênio (N) (Tabelas 5 e 7) foi dos animais que receberam suplemento múltiplo, que, consequentemente, tiveram maior excreção nas fezes e urina. Todavia, quando realizado o balanço de nitrogênio, os animais sob suplementação apresentaram maior $(\mathrm{P}<0,10)$ retenção de $\mathrm{N}$ (Tabela 7$)$ e, à medida que aumentou o nível de energia da alimentação, a retenção de N não foi alterada (Tabela 7), comprovando que as menores ofertas de suplemento foram suficientes para proporcionar uma relação energia:proteína favorável à retenção de N, o que pode justificar a proximidade entre os desempenhos, apesar do aumento linear crescente no GMD com os maiores fornecimentos de energia.

\section{Conclusões}

A oferta de suplementos em níveis crescentes durante o período da seca resulta em aumento do desempenho produtivo, contudo a magnitude deste desempenho reduz à medida que se aproxima dos níveis mais altos de oferta de suplemento. A suplementação para baixo consumo (aproximadamente $0,2 \%$ do peso vivo) pode ser fornecida aos tourinhos em fase de recria durante o período da seca para estimular o consumo de pasto, porém a máxima produção microbiana é obtida com ofertas medianas de suplementos (aproximadamente 0,5\% do peso vivo), na qual são observadas as melhores respostas de desempenho e características nutricionais. Altas ofertas de suplementos reduzem o consumo de pasto, contudo aumentam o desempenho produtivo, devido à maior ingestão de energia durante o período seco, podendo resultar em maiores taxas de lotação.

\section{Referências}

CASALI, A.O.; DETMANN, E.; VALADARES FILHO, S.C. et al. Influência do tempo de incubação e do tamanho de partículas sobre os teores de compostos indigestíveis em alimentos e fezes bovinas obtidos por procedimentos in situ. Revista Brasileira de Zootecnia, v.37, n.2, p.335-342, 2008.

CHEN, X.B.; GOMES, M.J. Estimation of microbial protein supply to sheep and cattle based on urinary excretion of purine derivatives - an overview of technical details. International Feed Resources Unit. Bucksburnd, Aberdeen: Rowett Research Institute, 1992. 21p. (Occasional publication).

CHIZZOTTI, M.L. Avaliação da casca de algodão para novilhos de origem leiteira e determinação da excreção de creatinina e produção de proteína microbiana em novilhas e vacas leiteiras. 2004. 132f. Dissertação (Mestrado em Zootecnia) Universidade Federal de Viçosa,Viçosa, MG.

DETMANN, E.; PAULINO, M.F.; ZERVOUDAKIS, J.T. et al. Cromo e indicadores internos na estimação do consumo de novilhos mestiços, suplementados, a pasto. Revista Brasileira de Zootecnia, v.30, n.5, p.1600-1609, 2001.

FUJIHARA, T.; ØRSKOV, E.R.; REEDS, P.J.; KYLE, D.J. The effect of protein infusion on urinary excretion of purine derivatives in ruminants nourished by intragastric nutrition. The Journal of Agricultural Science, v.109, n.1, p.7-12, 1987.

HALL, M.B. Calculation of non-structural carbohydrate content of feeds that contain non-protein nitrogen. Gainesville: University of Florida, 2000. p.A-25 (Bulletin 339).

LICITRA, G.; HERNANDEZ, T.M.; VAN SOEST, P.J. Standardization of procedures for nitrogen fractionation of ruminant feeds. Animal Feed Science and Technology, v.57, p.347-358, 1996.

MERTENS, D.R. Gravimetric determination of amylase-treated neutral detergent fibre in feeds with refluxing beakers or crucibles: collaborative study. Journal of AOAC International, v.85, p.1217-1240, 2002.

NATIONAL RESEARCH COUNCIL - NRC. Nutrient requirements of beef cattle. 7.ed. Washington, D.C.: National Academy, 1996. 242p.

NATIONAL RESEARCH COUNCIL - NRC. Nutrient requeriments of dairy cattle. 7.ed. National Academic Press. Washington, D.C., 2001. 381p.

OWENS, F.N.; GOETSCH, A.L. Ruminal fermentation. In: CHURCH, D.C. (Ed). The ruminant animal digestive physiology and nutrition. Englewood Cliffs: Simon \& Schuster, 1993. p.145-171.

PAULINO, M.F.; RUAS, J.R.M. Considerações sobre a recria de bovinos de corte. Informe Agropecuário, v.13, n.153/154, p.68-80, 1988.

PAULINO, M.F.; FIGUEIREDO, D.M.; MORAES, E.H.B.K. et al. Suplementação de bovinos em pastagens: uma visão sistêmica. 
In: SIMPÓSIO DE PRODUÇÃO DE GADO DE CORTE, 4., 2004, Viçosa, MG. Anais... Viçosa, MG: SIMCORTE, 2004. p.93-144. PAULINO, M.F.; DETMANN, E.; VALADARES FILHO, S.C. Suplementação animal em pasto: energética ou protéica? In: SIMPÓSIO SOBRE MANEJO ESTRATÉGICO DA PAstagem, 3., 2006, Viçosa, MG. Anais... Viçosa, MG: SIMFOR, 2006. p.359-392.

PAULINO, M.F.; DETMANN, E.; VALADARES FILHO, S.C. et al. Bovinocultura funcional nos trópicos. In: SIMPÓSIO DE PRODUÇÃO DE GADO DE CORTE, 6.; SIMPÓSIO INTERNACIONAL DE PRODUÇÃO DE GADO DE CORTE, 2., 2008, Viçosa, MG. Anais... Viçosa, MG: SIMCORTE, 2008. p.275-305.

PORTO, M.O.; PAULINO, M.F.; VALADARES FILHO, S.C. et al. Formas de utilização do milho em suplementos para novilhos na fase de terminação em pastagem no período das águas: desempenho e parâmetros nutricionais Revista Brasileira de Zootecnia, v.37, n.12, p.2251-2260, 2008.

SAMPAIO, C.B.; DETMANN, E.; LAZZARINI, I. et al. Rumen dynamics of neutral detergent fiber in cattle fed low-quality tropical forage and supplemented with nitrogenous compounds. Revista Brasileira de Zootecnia, v.38, n.3, p.560-569, 2009.

SILVA, D.J.; QUEIROZ, A.C. Análise de alimentos: métodos químicos e biológicos. 3.ed. Viçosa, MG: UFV, Imprensa Universitária, 2002. 165p.

SOUZA, M.A. Consumo, digestibilidade e dinâmica ruminal em bovinos alimentados com forragem tropical de baixa qualidade e suplementados com compostos nitrogenados e/ou carboidratos. 2007. 44f. Dissertação (Mestrado em Zootecnia) - Universidade Federal de Viçosa, Viçosa, MG.

TITGEMEYER, E.C.; ARMENDARIZ, C. K.; BINDEL, D.J. et al. Evaluation of titanium dioxide as a digestibility marker for cattle. Journal of Animal Science, v.79, p.1059-1063, 2001.

VALADARES, R.F.D.; BRODERICK, G.A.; VALADARES FILHO, S.C. et al. Effect of replacing alfalfa silage with high moisture corn on ruminal protein synthesis estimated from excretion of total purine derivatives. Journal of Dairy Science, v.82, n.11, p.2686-2696, 1999.

VALADARES FILHO, S.C.; MAGALHÃES, K.A.; ROCHA JUNIOR, V.R. et al. Tabelas brasileiras de composição de alimentos para bovinos. 2.ed. Viçosa, MG: DZO - DPI - UFV, 2006a. 329p.

VALADARES FILHO, S.C.; MORAES, E.H.B.K.; DETMANN, E. et al. Perspectivas do uso de indicadores para estimar o consumo individual de bovinos alimentados em grupo. In: REUNIÃO DA SOCIEDADE BRASILEIRA DE ZOOTECNIA, 44., 2006, João Pessoa. Anais.. João Pessoa, 2006b. (CD-ROM).

VALADARES FILHO, S.C.; PAULINO, P.V.R.; MAGALHÃES, K.A. et al. Exigência nutricional de zebuínos e tabelas de composição de alimentos, BR-Corte. Viçosa, MG: DZO UFV, 2006c. 142p.

VAN SOEST, P.J.; ROBERTSON, J.B. Analysis of forages and fibrous foods. Ithaca: Cornell University, 1985. 202p.

VERBIC, J.; CHEN, X.B.; MACLEOD, N.A. et al. Excretion of purine derivatives by ruminants. Effects of microbial nucleic acid infusion on purine derivative excretion by steers. Journal of Agricultural Science, v.114, n.3, p.243-248, 1990. 